rules of nomenclature, but would have to be based on the name of the first known genus.

There may be some justification for giving subfamiliar rank to Pithecanthropus and its relatives: but, here again the name should be Pithecanthropinæ, and not Anthropinæ. The rules of nomenclature have also been broken in the remaining proposed subfamily Homininæ, new names, for example, protosapiens, being suggested without reference to any previously available names. Again, Neanderthal man is ranked as a subspecific form, presumably the typical subspecies of $H$. primigenius, but labelled $H$. $p$. neandertalensis, and stated to be further divisible into "diverses races".

Thus, though the general arrangement may be fairly satisfactory so far as present knowledge goes, and is clearly based on the results of the most recent work, considerable revision of the names adopted is necessary besides modifications of the exact status of some of the forms included.

Medical College, W. C. OSMAN HILL. Colombo.

${ }_{1}$ Montandon, Revue Scientifique, 172-173 (March 1940).

${ }^{2}$ Pycraft, Man, 25, No. 99 (1925).

3 Zuckerman, NATURE, 145, 510 (1940).

- Dart, Nature, 115, 195, 199 (1925).

' Dart, Amer. J. Phys. Anthrop., 26, 176-186 (1940).

\section{Wild Seeds as Animal Feeding Stuffs}

IN his discussion of the supply of animal feeding stuffs $^{1}$ Dr. Norman C. Wright does not consider the collection and utilization of wild seeds such as horse chestnuts, acorns, and beech mast. Even if the whole of the present bumper crop of horse chestnuts and acorns were collected, it obviously would not counterbalance the estimated 10 million ton deficiency in imported foodstuffs, but would nevertheless provide a substantial addition to existing stocks which should not be allowed to go to waste.

When in good condition horse chestnuts and acorns are nutritious foods, their value depending largely on a high starch content. Horse chestnuts can be fed at a rate of $\frac{1}{2}-1 \mathrm{lb}$. per head, per day, for sheep, or 4-10 lb. for dairy cattle, or up to $20 \mathrm{lb}$. per day for fattening cattle ${ }^{2}$. Most animals soon become used to the slightly bitter flavour of the nuts, though pigs persistently refuse them. They can be fed fresh, but probably the best way of dealing with the nuts would be to collect them at central depots where facilities were available for drying and grinding to a meal. Mouldy nuts should not be fed unprepared. There must be thousands of trees in the country each now bearing $\frac{1}{2}-1$ cwt. of nuts.

Acorns have long been recognized as a valuable food for pigs, and the custom of pannage was strongly established in medieval England. They can be fed in small quantities to sheep and older cattle, but young cattle are susceptible to acorn poisoning, especially in years of drought, and should not be given them. Acorns can be fed fresh or dried. They keep for a long time in good condition if buried in pits in the same way as root crops.

A leaflet ${ }^{3}$ just published by the Ministry of Agriculture gives advice on the use of acorns, horse chestnuts and beech mast as feeding stuffs. During the War of 1914-18, collections of the nuts were made by schoolchildren and organized by the Board of
Education. Similar emergency measures might well be considered this year, but prompt action must be taken if the crop is to be utilized.

Royal Botanic Gardens,

R. Melville.

Kew. Sept. 7.

${ }^{1}$ Wright, N. C., NATURE, 146, 251 (1940).

${ }^{2}$ Anon., J. Board Agric., 21, 511-528 (1914).

s"Growmore" Leaflet No. 39, Min. of Agric. (1940).

\section{The Functions of Science}

There is one persistent feature of the current discussion on the social function of science which is very disquieting. Natural science offers to society at large, as well as to the individual man of science, several distinct benefits. One is simply the existence of an organized body of knowledge, accessible to those interested in it; for science, like every other intellectual discipline, is to be valued in itself for the truth which it contains. Another is the existence of a body of men trained to appreciate this knowledge, and acquainted with the arduous work of gathering data and interpreting them; good scientific work demands that the man of science should aim to be energetic, humble, both constructive and critical, neither sterile nor credulous, accustomed to think before he acts and to act upon his conclusions. A third social benefit is conferred by the applicability of scientific knowledge to provide techniques for large-scale handling of matter, and hence for the improvement of the material conditions of life; properly used, this last function of science can confer real benefits, for example, by raising the life of the poor to a more tolerable standard.

This third aspect of the social function of science is ( $I$ submit) in danger of being emphasized to the neglect of the others, of no less importance. The discussion exhibits much goodwill and much concern for social justice, but not always, perhaps, an adequate knowledge either of the nature of science or of the nature of man and society. That science is pursued in the first place for its truth; that it cannot dogmatize about questions which touch on philosophy; that economies is not independent of ethics; that human nature demands culture, family life, and spiritual values, before material comfort-all these considerations are too often ignored. This tendency is lamentable. It would lead us altogether too close to the Nazi view of science (already sufficiently exposed in NATURE), with its insistence on Anwendbarkeit and rejection of the notion of science as an effort to reach certain truths.

A more liberal view, which does not neglect the intellectual values of natural science, is widely held, but is unfortunately less vocal ${ }^{1}$. A greater attention to the notion of pure science, as an ordered study with its own principles and its own intrinsic modes of development, is needed as a corrective to the current one-sided development of views on the social function of science. The admirable leading article in Nature on "The Repudiation of Truth" ", and a recent letter from Dr. J. I. O. Masson ${ }^{3}$, will repay attention in this connexion.

Queen's College,

E. F. Caldin.

Oxford. August 24.

${ }^{1}$ See, however, Polanyi, "Rights and Duties of Science", Manchester School of Economic Social Studies, Oct. 1939, p. 175.

2 NATURE, 145, 871 (1940).

${ }^{3}$ NATURE, 145, $855(1940)$. 